\title{
Occupational exposure to conventional antineoplastic drugs: can it be further limited?
}

\author{
Nicolas Simon $\odot, 1,2$ Pascal Odou, ${ }^{1}$ Bertrand Décaudin, \\ Pascal Bonnabry $\odot,{ }^{2}$ Sandrine Fleury Souverain ${ }^{2}$
}

In 2019, we celebrated the 40th anniversary of the famous article published by Falck et al, dealing with the mutagenicity of the urine of nurses who were in daily contact with conventional antineoplastic drugs. ${ }^{1}$ Since the publication of this article, highlighting the hazard of handling such drugs, extensive literature has flowed, in order to:

- identify the different sources of contamination

- characterise the risks associated with this occupational exposure

- evaluate the levels of contamination

- assess new technologies/work processes and organisations contributing to limit the spread of contamination

- assess different decontamination solutions.

All this knowledge has raised our level of vigilance on this issue and encouraged us to upgrade our practices constantly. Scientific data have been obtained through technological advances and in many different operating conditions, the latter making it difficult to define a fair protection level. Moreover, a lack of relevant clinical references and toxicological values has led to a continuous exploration for protective measures. Forty years after the first report of the hazard of conventional antineoplastic drugs, the only certitude is that there are ways of reducing occupational exposurebut can complete elimination be expected?

The first aspect concerns the assessment of surface contamination, which was made according to local operating conditions and specifications. ${ }^{23}$ The lowest exposure level was often based upon the performances of the analytical methods used. However, comparison of results from published

\footnotetext{
'Univ. Lille, CHU Lille, EA 7365 - GRITA - Groupe de Recherche sur les Formes Injectables et les Technologies Associées, Lille, France

${ }^{2}$ Pharmacy, Geneva University Hospitals and School of Pharmaceutical Sciences, University Hospital of Geneva, University of Lausanne, Geneva, Switzerland
}

Correspondence to Dr Nicolas Simon, GRITA Grp Rech Formes Injectables, LILLE Cedex 59006, France; nicolas.simon@univ-lille.fr studies is difficult as performance levels vary.

The most important point therefore is to validate an assay that takes into consideration present standard requirements, including the wiping step, to ensure the good reproducibility of results over time. ${ }^{4-6}$ Each unit could select the antineoplastic drugs best adapted to their range of preparations. The USP800 monograph proposed some contaminants as contamination markers (eg, methotrexate, 5-fluorouracil, platinum salts or cyclophosphamide). Pharmacists could choose other contaminants depending notably on their hazardous character and their varying physicochemical properties. ${ }^{2}$ New innovative techniques with higher sensitivity make it difficult to define surface contamination thresholds. ${ }^{4}$ Further studies are required to determine the best monitoring frequency to standardise the procedure based on the number of preparations compounded or the amount of drug handled. Indeed, contamination needs to be monitored more frequently in high-rate production units than in low-rate production ones. This would help to establish contamination profiles for compounding units and obtain more comparable results from different studies.

The second aspect concerns safety measures. The American Society of Hospital Pharmacists recently published updated recommendations in 2018. ${ }^{8}$ The introduction of decontamination/deactivation solutions to remove residual contamination was clearly introduced by the USP800 monograph. ${ }^{7}$ However, practitioners have to choose the best decontamination solution for a compounding unit by considering other factors than simply the efficacy of the solution ${ }^{9}$ - for example, situations that can occur in a compounding unit, such as a critical incident leading to a massive contamination exposure in a short space of time as well as continuous exposure to low doses through daily activity. ${ }^{10}$ Whatever the situation, the continuous training of healthcare workers must take place to improve safety.

Finally, would it not be a simple but radical protection strategy to combine all measures? But within what limits? Must we systematically combine protective means in order to reach safe individual contamination levels? Beyond the efficacy of each protective means, it would probably be more logical to consider a protection strategy as a whole, by discussing what combinations will give the same results. The biggest issue is the cost associated with adding new measures. Indeed, pharmacists need to adapt the confinement strategy to the problems encountered in their compounding units. Two protective measures need to be implemented first: control of the environment, and implementation of an efficient deactivation/decontamination method. The place of closed-system drug transfer devices could be considered according to the results of environmental contamination or the contaminant.

To conclude, 40 years after Falck's publication, we need clear guidelines on the actions to be undertaken in our facilities. Practices have to be standardised to establish a clear relationship between surface contamination levels and the protective measures implemented. Further studies are required for a better definition of contamination thresholds; more reliable biological markers would provide better protection to healthcare workers.

\section{Twitter Pascal Bonnabry @bonnabry}

Acknowledgements The authors thank Alexandra Tavernier, MA (University of Glasgow UK), Professeur Agrégée (France) for her assistance in correcting and editing the text. Dr Nicolas Simon was offered a grant by la Société Française de Pharmacie Clinique and by la Fondation pour la Recherche en Pharmacie Hospitalière and les laboratoires AstraZeneca for his post-doctoral position in the University Hospital of Geneva.

Contributors All the authors have contributed to this article and have approved the submitted version.

Funding The authors have not declared a specific grant for this research from any funding agency in the public, commercial or not-for-profit sectors.

Competing interests None declared.

Patient consent for publication Not required.

Provenance and peer review Not commissioned: internally peer reviewed.

(c) European Association of Hospital Pharmacists 2020. No commercial re-use. See rights and permissions. Published by BMJ.

\section{Check for updates}

To cite Simon N,

Odou P, Décaudin B, et al. Eur J Hosp Pharm 2020;27:251-252.

Published Online First 16 December 2019

Eur J Hosp Pharm 2020;27:251-252.

doi:10.1136/ejhpharm-2019-002165

ORCID iDs

Nicolas Simon http://orcid.org/0000-0001-5257-440X 
Pascal Bonnabry http://orcid.org/0000-0002-8690649X

\section{REFERENCES}

1 Falck K, Gröhn P, Sorsa M, et al. Mutagenicity in urine of nurses handling cytostatic drugs. Lancet 1979;313:1250-1.

2 Guichard N, Guillarme D, Bonnabry P, et al. Antineoplastic drugs and their analysis: a state of the art review. Analyst 2017;142:2273-321.

3 Petit M, Curti C, Roche M, et al. Environmental monitoring by surface sampling for cytotoxics: a review. Environ Monit Assess 2017;189.
4 Connor TH, Zock MD, Snow AH. Surface wipe sampling for antineoplastic (chemotherapy) and other hazardous drug residue in healthcare settings: methodology and recommendations. J Occup Environ Hyg 2016;13:658-67.

5 Guichard N, Fekete S, Guillarme D, et al. Computerassisted UHPLC-MS method development and optimization for the determination of 24 antineoplastic drugs used in hospital pharmacy. J Pharm Biomed Anal 2019;164:395-401.

6 Guichard N, Rudaz S, Bonnabry P, et al. Validation and uncertainty estimation for trace amounts determination of 25 drugs used in hospital chemotherapy compounding units. J Pharm Biomed Anal 2019;172:139-48.
7 US Pharmacopeia. USP General chapter <800> Hazardous drugs - handling in healthcare settings. Available: www.usp.org [Accessed 15 May 2019].

8 Power LA, Coyne JW. ASHP guidelines on handling hazardous drugs. Am J Health Syst Pharm 2018;75:1996-2031.

9 Simon N, Odou P, Décaudin B, et al. Efficiency of degradation or desorption methods in antineoplastic drug decontamination: a critical review. J Oncol Pharm Pract 2019;25:929-46.

10 Simon N, Odou P, Décaudin B, et al. Chemical decontamination of hazardous drugs: a comparison of solution performances. Annals of Work Exposure and Health 2019. 